


\section{Ferner in unserm Verlag erschienene .Terke}

\section{über Chemie:}

Lehrbuch der anorganischen Chemie filr Studierende an Universitïten und technischen Hochschulen von Professor Dr. A. F. Holleman. Sechzehnte, verbesserte Auflage. Mit zahlreichen Figuren. Groß-Oktav. XII, 476 Seiten. Geb. M. 28.-.

Lehrbuch der organischen Chemie fitr Stadierende an Universithiten und technisehen Hochschulen von Professor Dr. A. F. Holleman. Fünfzehnte, verbesserte Auflage. Mit zahlreichen Figuren. GroB-Oktav. XII, 496 Seiten. Geb. M. 28.-.

Einfache Versuche auf dem Gebiete der organischen Chemie. Eine Anleitung für Studierende, Lehrer an höheren Schulen und Seminaren sowie zum Selbstunterricht. Deutseh durch Prof. Dr. Wilb. Meigen. Von A. F. Holleman, o. Prof. a. d. Universität Amsterdam. Zweite, verbesserte Auflage. Mit 2 Figuren. Olstav. X, 94 Seiten. Geb. M. 3.- + $100 \%$.

Die Praxis des organischen Chemikers von Ludwig Gattermann, weil. Geh. Hofrat, Prof. a. d. Universität Freiburg. Fünfzehnte, verbesserte Auflage. Mit 95 Abbildungen und 2 Tabellev. GroB-Oktav. XII, 368 Seiten. Geb. M. 45.-

Knrzes chemisehes Praktikum für Mediziner und Landwirte von Fritz Arndt, o. Professor a. d. Universität Breslau. Dritte und vierte, verbesserte Auflage. Grob-Oktav. XIII, 96 Seiten.

Geb. M. 10.-

Qualitative Analyse unorganischer Substanzen von Hein rich Biltz, o. Prof. a. d. Universität Breslau. Achte bis zehnte Auflage. Mit 8 Figuren. Grob-Oktav. 64 Seiten. Geb. M. 14.-.

Experimentelle Einführung In die unorganische Chemie von Heinrich Biltz, o. Professor a. d. Universität Breslau. Neunte bis elfte Auflage. Mit 15 Figuren. GroB-Oktav. VI, 130 Seiten.

Geb. M. 20.-.

Erläuterungen zum Gebranch organischer Reagentien in der anorganischen Analyse von Dr. Martin Müller, Assistent am Laboratorium für angewandte Chemie der Univers. Leipzig. GroB-Oktav. VI, 55 Seiten.

Geh. M. 10.-

Vereinigung wissenschafticher Verleger

Walter de Gruyter \& Co. - vormals G. J. Göschen'sche Verlagghandlung - J. Guttentag, Verlagsbuchhandlung -

Georg Reimer - Karl J. Trübner -

Veit \& Comp. - Berlin W. 10

und Leipzig 


\title{
Chemische Versuche aus dem Gebiete der anorganischen Chemie
}

\author{
Herqusgegeben von
}

J. K. König

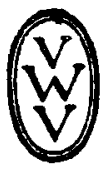

Berlin und Leipzig 1921

Vereinigung wissenschaftlicher Verleger Walter de Gruyter \& Co.

rornals G. J. Göschen'sche Verlagshandlung :: J. Guttentag, Verlagzbuchbandlung :: Goorg Relmer :: Karl J. Tribner :: Veit \& Comp. 
Alle Rechte, einschließlich des Übersetzungsrechts, vorbehalten. Druck von Metzger \& Wittig in Leipzig. 